\title{
Cell death in Leishmania induced by stress and differentiation: programmed cell death or necrosis?
}

\author{
H Zangger ${ }^{1}$, JC Mottram ${ }^{2}$ and N Fasel ${ }^{*, 1}$ \\ 1 Institute of Biochemistry, University of Lausanne, ch. des Boveresses 155, \\ 1066 Epalinges, Switzerland \\ 2 Wellcome Centre for Molecular Parasitology, University of Glasgow, 56 \\ Dumbarton Rd, Glasgow G11 6NU, Scotland, UK \\ * Corresponding author: Prof. Nicolas Fasel, Institute of Biochemistry, \\ University of Lausanne, Ch. des Boveresses 155, 1066 Epalinges, Switzerland. \\ Tel: ++41-21-692 57 32; Fax: ++41-21-692 57 05; \\ E-mail: Nicolas.Fasel@ib.unil.ch
}

Received 19.11.01; revised 19.4.02; accepted 2.5.02

Edited by Y Kuchino

\begin{abstract}
Unicellular organisms, such as the protozoan parasite Leishmania, can be stimulated to show some morphological and biochemical features characteristic of mammalian apoptosis. This study demonstrates that under a variety of stress conditions such as serum deprivation, heat shock and nitric oxide, cell death can be induced leading to genomic DNA fragmentation into oligonucleosomes. DNA fragmentation was observed, without induction, in the infectious stages of the parasite, and correlated with the presence of internucleosomal nuclease activity, visualisation of 45 to $59 \mathrm{kDa}$ nucleases and detection of TUNEL-positive nuclei. DNA fragmentation was not dependent on active effector downstream caspases nor on the lysosomal cathepsin L-like enyzmes CPA and CPB. These data are consistent with the presence of a caspase-independent cell death mechanism in Leishmania, induced by stress and differentiation that differs significantly from metazoa.

Cell Death and Differentiation (2002) 9, 1126-1139. doi:10.1038/sj.cdd.4401071
\end{abstract}

Keywords: Leishmania; programmed cell death; necrosis; DNA fragmentation; cysteine proteases; host-parasite interaction

Abbreviations: BMM, bone marrow macrophage; $\mathrm{CPA}$, cysteine protease a; CPB, cysteine protease b; DTT, dithiothreitol; LPS, lipopolysaccharide; MNase, micrococcal nuclease; NO, nitric oxide; PCD, programmed cell death; $\triangle c p a, C P A$ null mutant; $\triangle c p b$, CPB null mutant; $\triangle c p a / c p b, C P A$ and $C P B$ null mutant; $\gamma$-IFN, gammainterferon

\section{Introduction}

Apoptosis, or programmed cell death (PCD), is a suicidal pathway that has clear benefits for multicellular organisms, in eliminating cells which are damaged, infected, or are simply no longer required. Thus, in mammals, PCD is extremely important during development ${ }^{1}$ and in immune system functions. ${ }^{2,3}$ In contrast to necrosis, cells that die by apoptosis are not lysed, but are eliminated by phagocytosis, thus preventing the development of an inflammatory response.

The benefits of PCD in unicellular organisms are less evident. There are, however, an increasing number of reports that describe that some unicellular organisms may also undergo PCD under certain conditions. ${ }^{4-6}$ The most studied systems are macronuclear elimination in the protozoa Tetrahymena thermophila ${ }^{7-12}$ and differentiation in the slime mold Dictyostelium discoideum. ${ }^{13-17}$ Features reminiscent of apoptosis were also observed in the dinoflagellate Peridinium gatunense ${ }^{18}$ and a simple and ancestral PCD mechanism was suggested in bacterial populations (restriction-modification system). ${ }^{5,19,20}$

The protozoan parasite Leishmania is a member of the order Kinetoplastida including also Trypanosoma species. It is the causative agent of one of the most important human parasitic disease, leishmaniasis, which may lead, according to the species, to self-healing cutaneous lesions, mucocutaneous lesions or fatal, generalised visceral infection. The promastigote form of the parasite, flagellated and extracellular, resides in the midgut of the insect vector, the female sandfly (Phlebotomus). It differentiates from a proliferating non-infectious procyclic to a non-dividing infectious metacyclic promastigote. Upon bloodmeal by the sandfly, the parasite infects the mammalian host macrophages and differentiates into amastigotes that can survive and divide in the macrophage phagolysosome.

Among the Kinetoplastida, several studies have shown that DNA laddering (although not very pronounced), chromatin compaction and membrane blebbing are found in dying procyclic forms of Trypanosoma brucei infecting tsetse flies, ${ }^{21,22}$ and in $T$. cruzi during the in vitro differentiation into trypomastigotes. ${ }^{23}$ In $T$. brucei procyclic forms, similar morphological features of apoptosis could be induced, in vitro, with concanavalin A treatment, ${ }^{24,25}$ or under oxidative stress. ${ }^{26}$ Additionally, Leishmania amazonensis promastigotes display DNA laddering and chromatin condensation in dense clusters (leading to the breakdown of the nuclear membrane) upon heat-shock, corresponding to classical features of PCD. ${ }^{27}$ PCD could therefore be present during differentiation and stress, which are two important situations in the life cycle of trypanosomatids.

Very little is known about the pathways and the proteins implicated in this potential PCD process in unicellular organisms. Only recently, a few molecules have been implicated in PCD of protozoa and ciliates. In dying Trypanosoma cruzi epimastigotes, elongation factor 1alpha was shown to relocalise from the cytoplasm into the nucleus ${ }^{28}$ whereas in Trypanosoma brucei rhodesiense, prohibitin, an homologue of a mammalian protooncogene and RACK, a receptor for activated protein 
kinase $\mathrm{C}$, were shown to be up-regulated in procyclic Trypanosoma induced to undergo cell death. ${ }^{25,29}$ In Tetrahymena and in Stylonychia, morphological changes and proteins possibly involved in programmed DNA degradation have been described. ${ }^{8,12,30}$ However, none of these reports provide answers about the implicated pathways except in the case of death in Trypanosoma brucei, which was shown to be $\mathrm{Ca}^{2+}$-dependent when induced by reactive oxygen species (ROS). In this case, however, parasites expressing mouse $\mathrm{Bcl}-2$ were not protected from ROS even though protection from mitochondrial dysfunction and ROS have been reported for mammalian cells. ${ }^{26}$

Although no adaptor domains such as Death domains, DED, CARD or Pyrin have been found in any lower eukaryote, homologues of proteins implicated in the process of cell death, may exist in unicellular organisms. ${ }^{31-33}$ In two recent studies, ${ }^{34,35}$ cell death has been studied in more detail. Several cytoplasmic and nuclear features of apoptosis, such as mitochondrial transmembrane potential loss, cytochrome $c$ release, nuclear condensation and fragmentation, were observed when staurosporine, a drug known to induce apoptosis in mammalian cells was used to stimulate cell death. ${ }^{34}$ Using human isolated nuclei as targets, nuclear DNA degradation was observed when a staurosporine treated cytoplasmic extract of promastigotes was used. The DNA fragmentation was prevented in the presence of the inhibitor E64 suggesting that cytoplasmic extracts of staurosporine treated parasites contained cysteine proteases activity involved in the DNA fragmentation process. In a parallel study on Leishmania donovani, ${ }^{35}$ similar evidence of cell death was obtained when parasites were treated with Pentostam or amphotericin B. Some features of PCD are reported such as nicked DNA in the nucleus, DNA fragmentation, mitochondrial transmembrane potential decrease and cleavage of the cell permease caspase specific substrate PhiPhiLux. Using specific inhibitors, evidence for the presence of caspase-like activity but not cathepsin or calpain was reported.

Although these recent reports provide some evidence of the existence of cell death in unicellular organisms that show some similarities to PCD, knowledge of the effector and regulatory molecules is still very limited. Clearly it is necessary to identify effector and regulatory molecules of cell death in Leishmania in order to distinguish between PCD and necrosis. The complete sequence of the Leishmania and Trypanosoma genomes and their functional analysis will be important in this regard. Identification of genes closely related to caspases, the metacaspases, ${ }^{33}$ in the genome of Trypanosoma brucei may be a first step in this direction.

The frontier between necrosis and apoptosis is merging as it is further studied in various mammalian cell lines and a variety of organisms. Four patterns of death are emerging; apoptosis, which is caspase-dependent, apoptosis-like PCD, which is generally caspase-independent, necrosis-like PCD, which has some features of apoptosis and accidental necrosis. ${ }^{36}$ In this work cell death in the human parasite Leishmania was investigated, especially during differentiation and stress/killing pathways. With the use of genomic DNA fragmentation studies, SDS-DNAPAGE, DEVDase activity and TUNEL assays, it is demonstrated that Leishmania cell death shows some physical features associated with mammalian PCD, but that the pathways leading to death in Leishmania are certainly distinct.

\section{Results \\ DNA laddering and nuclease activity in the infectious stages of Leishmania}

Intact nuclei from different stages of the parasite life cycle were analyzed for chromatin compaction. Genomic DNA fragmentation into oligonucleosomes was visible in stationary phase promastigotes and especially in amastigotes from $L$. major (Figure 1A, lanes 2-3). It was not, however, detectable in proliferating, logarithmic phase promastigotes (Figure 1, lane 1). The same results were observed for $L$. mexicana promastigotes and amastigotes (data not shown). L. mexicana in vitro-differentiated amastigotes (or 'axenics') also showed this type of DNA degradation (Figure 1A, lane 4).

If genomic DNA is degraded in vivo, it should reflect the action of an intrinsic endonuclease from the parasite. To demonstrate this activity, nuclei preparations were incubated alone, without addition of any exogenous nuclease, under conditions that allowed micrococcal nuclease (MNase) digestion, for up to $30 \mathrm{~min}$ (Figure 1B). As expected, no DNA degradation was observed using logarithmic phase promastigote nuclei, even following $30 \mathrm{~min}$ incubation (Figure 1B, lanes 1-3). At this stage, this absence of degradation was not due to a specific resistance of the chromatin, as the genomic DNA was efficiently fragmented into oligonucleosomes following addition of MNase under the same conditions (Figure 1B, lanes 5-6). When nuclei from stationary phase promastigotes (Figure 1B, lanes 9-11) or amastigotes (data not shown) were incubated alone (10 to $30 \mathrm{~min}$ ), DNA degradation was further increased, resulting in a nucleosomal fragmentation pattern which was comparable to that obtained following MNase action (similar sizes of oligomers) (Figure 1B, lanes 13-14). Identical results were obtained with $L$. mexicana (data not shown). These results indicate that the endonucleases responsible for DNA degradation are present and still active in the nuclei preparation of the infective stages of Leishmania.

As an initial attempt to examine in greater detail the activity of these endonucleases, the same experiment was performed following the removal or addition of divalent ions known to be involved in the activity of certain nucleases. Firstly, as for many other nucleases, MNase activity was blocked by the addition of EDTA, which chelates its necessary $\mathrm{Ca}^{2+}$ or $\mathrm{Mg}^{2+}$ cofactors, as demonstrated on intact nuclei (Figure 1B, lane 7). EDTA addition on intact, logarithmic phase nuclei did not show any effect (Figure $1 \mathrm{~B}$, lane 4). When EDTA was added on stationary nuclei alone, the endogenous nuclease activity was not blocked, but in contrast was further increased, as revealed by strong nucleosomal degradation (Figure 1B, lane 12). When both MNase and EDTA were added to these nuclei, it lead to a 

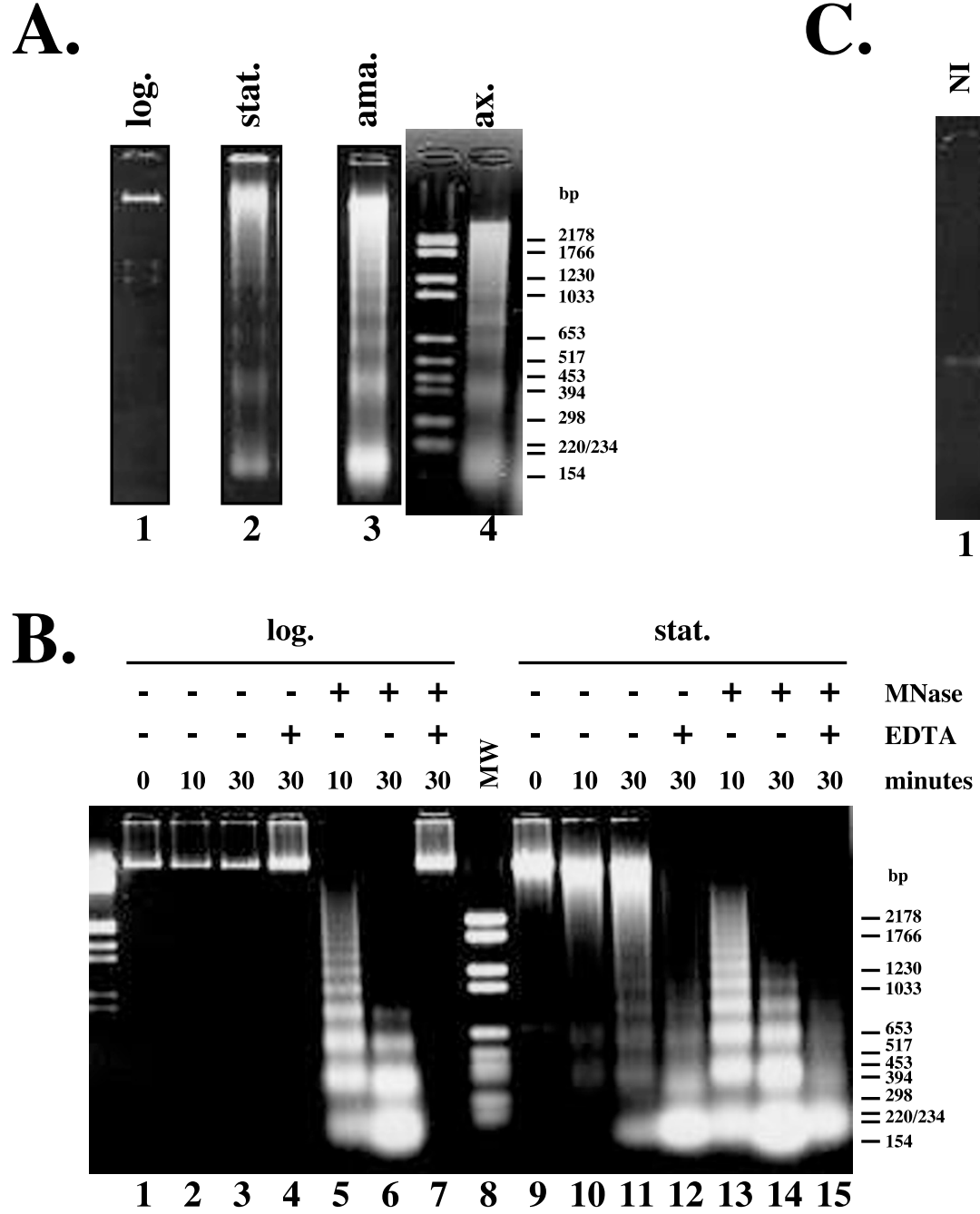
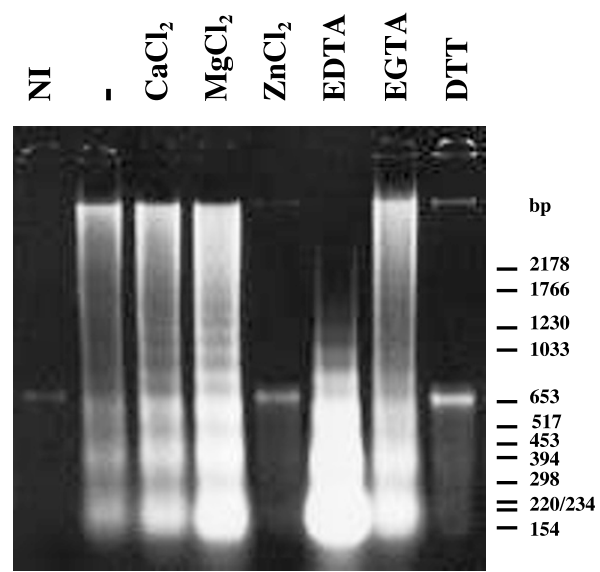

$\begin{array}{llllllll}1 & 2 & 3 & 4 & 5 & 6 & 7 & 8\end{array}$

Figure 1 DNA laddering and associated nuclease activity in the infective stages of Leishmania. DNA was extracted from nuclei, precipitated and loaded on $2 \%$ agarose gels. (A) Genomic DNA from intact nuclei (no incubation). log./stat./ama., L. major logarithmic, stationary phase promastigotes and amastigotes. ax., L. mexicana (wild-type) axenic parasites, following 5 days of differentiation. (B) Nuclei from logarithmic (log.) and stationary (stat.) phase promastigotes were incubated in the presence or absence of MNase $(5 \mathrm{mU} / \mu \mathrm{g})$ for the indicated times at $30^{\circ} \mathrm{C}$ in $1 \mathrm{mM} \mathrm{CaCl}$. EDTA was at a final concentration of $5 \mathrm{mM}$. $M W$, molecular weight marker. (C) Stationary phase promastigote nuclei were incubated in the presence, or absence (-), of $5 \mathrm{mM} \mathrm{CaCl}, \mathrm{MgCl}_{2}, \mathrm{ZnCl}_{2}$, $\mathrm{EDTA}_{2}, \mathrm{EGTA}$ or DTT for $30 \mathrm{~min}$ as indicated. $\mathrm{NI}$, no incubation. (D) Logarithmic phase promastigote nuclei were incubated with $\mathrm{MNase}$ for $30 \mathrm{~min}$ in the presence of $5 \mathrm{mM} \mathrm{ZnCl} \mathrm{C}_{2}$ where indicated. The presence of the $650 \mathrm{bp}$ band (mostly visible in gel C) is likely due to contamination of mini-circles from the kinetoplast

fragmentation pattern which was comparable to the one observed with EDTA alone (Figure 1B, lane 15).

Similar experiments were subsequently performed on stationary phase nuclei, following the addition of different divalent ions. Without incubation, fragmentation was practically not detected. Only the kinetoplast minicircle DNA (ca 650 bp) is visible (Figure 1C, lane 1). Fragmentation was, however, visible following $30 \mathrm{~min}$ incubation (Figure 1C, lane 2). As previously shown, EDTA activated DNA degradation (Figure 1C, lane 6). No increase of degradation was observed upon addition of $\mathrm{Ca}^{2+}$ (Figure 1C, lane 3) or $\mathrm{Mn}^{2+}$ (data not shown), while $\mathrm{Mg}^{2+}$ seemed to increase the effect slightly (Figure 1C, lane 4). The addition of the $\mathrm{Ca}^{2+}$-specific chelator EGTA had no strong effect, as expected (Figure 1C, lane 7). Not surprisingly, the addition of the reducing agent DTT was sufficient to destroy nuclease activity (Figure $1 \mathrm{C}$, lane 8 ). Finally, $\mathrm{Zn}^{2+}$ was able to totally block nucleosomal fragmentation (Figure $1 \mathrm{C}$, lane 5). As no classical cofactor appeared to be necessary for endogenous nuclease activity, the inhibitory effect of $\mathrm{Zn}^{2+}$ could explain the surprising activation by EDTA, through chelating endogenous $\mathrm{Zn}^{2+}$ present in the nuclei preparations. The effect of $\mathrm{Zn}^{2+}$ addition on MNase activity was also examined. Under the same conditions, $\mathrm{Zn}^{2+}$ addition (Figure 1D, lane 3) also blocked the activity of MNase (Figure 1D, lane 2) (see also intact DNA in Figure 1D, lane $1)$.

\section{In vitro nuclease activity assay}

A simple in vitro assay was developed to study the nuclease activity in Leishmania. Amastigote nuclear extracts, with high 
nuclease activity, were prepared by digesting the endogenous DNA from amastigote nuclei with MNase, followed by blocking of the exogenous MNase activity with EDTA. The nuclease activity of such amastigote nuclear extracts was then tested on a plasmid (pGEM-1), in the presence of EDTA to block MNase activity. A strong degradation of the plasmid by the endogenous nucleases was observed following 10 or $30 \mathrm{~min}$ of incubation (Figure 2A, lanes 2-3), when compared to the intact plasmid (Figure 2A, lane 1). As expected, the degradation pattern in this case is smeary (not oligonucleosomal), as the plasmid used was 'naked' (no chromatin structure; thus endonucleases cleave the plasmid at any site). Confirming previous results, the nuclease activity was also blocked by $\mathrm{Zn}^{2+}$ addition prior to incubation (Figure 2A, lane 4). The assay was repeated using logarithmic and stationary phase promastigote nuclear extracts. As expected, the results correlate with previous observations, which showed no nuclease activity in logarithmic phase promastigotes and weaker nuclease activity in stationary phase promastigotes as compared to amastigotes (data not shown). As found with other DNases, 10 min pre-incubation of the amastigote nuclear extract at $80^{\circ} \mathrm{C}$ was sufficient to totally destroy the nuclease activity (Figure 2B, lane 5), while heating for 2 min lead to a partial inhibition (Figure 2B, lane 4).

To confirm that the nuclease activity from amastigote extracts was able to degrade intact chromatin structure into oligonucleosomes (endonuclease activity), an in vitro nuclease assay was also performed on logarithmic phase promastigote nuclei rather than plasmid DNA. Internucleo- somal degradation was not visible in the nuclei alone (Figure 2C, lane 1). Amastigote extract was able to provoke a progressive nucleosomal fragmentation of the intact chromatin following 10 and 30 min incubation (Figure 2C, lanes 2-3). This fragmentation was similar to that observed following digestion with the endonuclease MNase (see Figure 1B, lanes 5-6). Lane 4 of Figure $2 \mathrm{C}$ indicates that the amastigote nuclear extract no longer contained endogenous DNA.

\section{SDS - DNA-PAGE analysis}

Parasitic nuclease(s) implicated in DNA fragmentation were visualised using SDS-DNA-PAGE. With this technique, incorporated DNA was used as a substrate for directly testing nuclease activity on gels. MNase was first loaded as a positive control and a $20 \mathrm{kDa}$ activity band, whose presence is $\mathrm{Ca}^{2+}$. dependent, ${ }^{37}$ was identified as expected (Figure 3A, lane 1). Five nuclease bands (approximately $45-55 \mathrm{kDa}$ ) in $L$. major amastigote nuclei (Figure 3B, lane 1) and four bands (approximately $51-59 \mathrm{kDa}$ ) in L. mexicana axenics (Figure $3 \mathrm{~B}$, lane 2) and amastigotes (data not shown) were visible on the gel. Correlating with the above DNA fragmentation data, a barely detectable amount of nuclease banding appeared in the logarithmic phase promastigote nuclei (Figure 3A, lanes 2-3 for L. major, and Figure 3C, lane 1 for L. mexicana). Considering that approximately five times the amount of stationary phase protein was required to obtain a level of activity comparable to the level of activity detected in

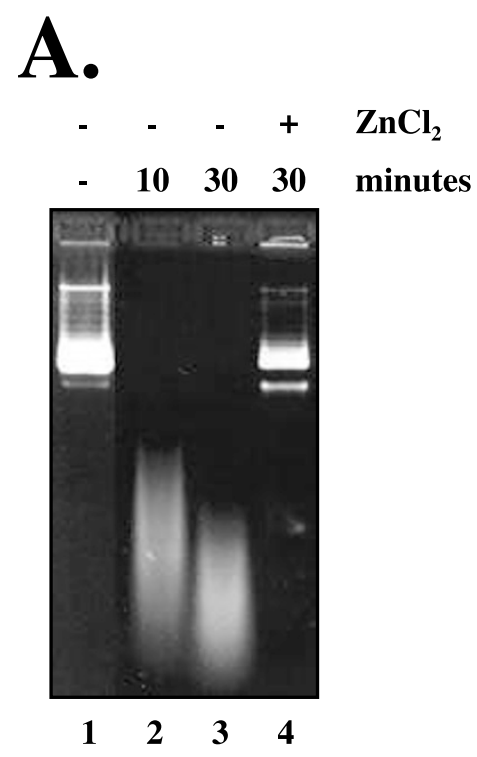

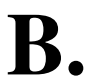

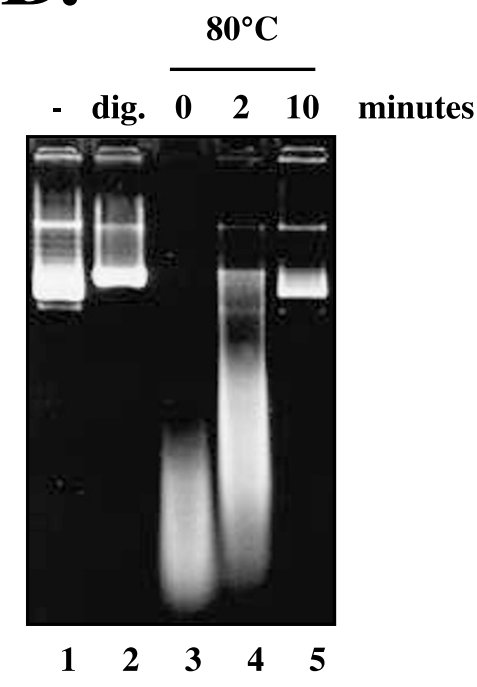

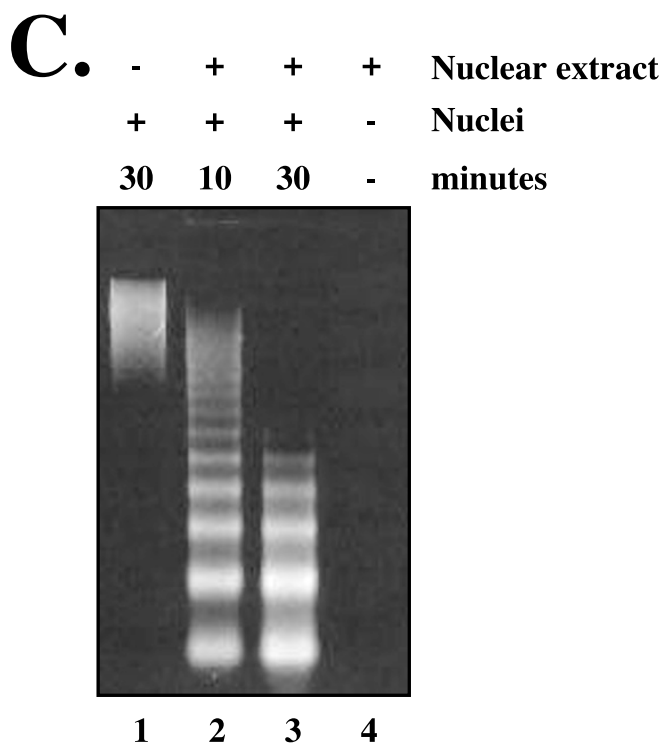

Figure 2 The parasitic DNase activity is inhibited by $\mathrm{Zn}^{2+}$ addition or heating. Amastigote nuclear extract was prepared by digesting endogenous DNA from the nuclei with MNase (under the conditions used for MNase assays). MNase was then blocked by the addition of $5 \mathrm{mM}$ EDTA. One $\mu \mathrm{g}$ of the pGEM-1 plasmid (A,B) or $30 \mu \mathrm{g}$ of log. promastigote nuclei $(\mathbf{C})$ were incubated with $4 \mu \mathrm{g}(\mathbf{A}, \mathbf{B})$ or $15 \mu \mathrm{g}(\mathbf{C})$ of nuclear extract at $30^{\circ} \mathrm{C}$ with $5 \mathrm{mM}$ EDTA. Following the incubation, DNA was extracted, precipitated and loaded on a $2 \%$ agarose gel. (A) Heat-inactivation. Before the 30 min incubation at $30^{\circ} \mathrm{C}$, the plasmid was linearised with BamHI (dig., lane 2), or the nuclear extract was incubated at $80^{\circ} \mathrm{C}$ for 0,2 or $10 \mathrm{~min}$ as indicated (lanes $\left.3-5\right)$. Lane $1(-)$ : pGEM-1 alone. (B) Zn ${ }^{2+}$ inhibition. pGEM-1 was incubated with the nuclear extract for 10 or $30 \mathrm{~min}$, with or without addition of $5 \mathrm{mM} \mathrm{ZnCl}_{2}$ as indicated (lanes 2-4). Lane 1 (-): pGEM-1 alone. (C) Intact chromatin digestion by amastigote nuclear extract. Logarithmic phase promastigote nuclei (nuclei) were incubated with amastigote nuclear extracts (nuclear extract) for the indicated times. Lane 4, amastigote nuclear extract alone 
amastigotes, we can estimate that five times less activity is present in stationary as compared to amastigote parasites (Figure 3A, lanes 4-5 for $L$. major, data not shown for $L$. mexicana). It is therefore likely that the nucleases visualized by SDS-DNA-PAGE were responsible for the DNA fragmentation and nuclease activity described. In support of this, the presence of the banding pattern for nuclease activity did not require the addition of divalent ions (Figure 3B,C), and the activity was destroyed by a $80^{\circ} \mathrm{C}$ pre-incubation step (data not shown), as was previously observed in the DNA fragmentation assays.

\section{Detection of TUNEL-positive nuclei}

In addition to demonstrating DNA fragmentation and nuclease activity, it was important to analyze the localisation of this process. To this end, the TUNEL assay, which is routinely used to detect mammalian apoptotic cells, was employed. TUNEL-positive nuclei were not observed in logarithmic phase promastigotes, as expected due to the absence of DNA laddering at this stage. In stationary phase promastigote, a small percentage $(1-2 \%)$ of nuclei were stained (Figure 4A). This percentage increased to approximately $20-30 \%$ in mouse lesion isolated-amastigotes (Figure 4B), correlating with the strong nucleosomal DNA fragmentation data previously observed (Figure 1A, lane 3). Similar observations were seen for $L$. mexicana (data not shown). Immunofluorescence assays using an antibody directed against single-stranded DNA to detect apoptotic nuclei was also tested (Alexis). With this assay, a similar percentage of amastigote positive nuclei were observed (data not shown). Taken together, these results support the previous nuclease and DNA laddering observations and the apoptotic-like nature of this death process.

To confirm these results in a closer situation to in vivo infection, the TUNEL assay was performed on in vitro infected macrophages. In this assay, mouse bone marrow macrophages (BMM) were infected with $L$. major or $L$. mexicana stationary phase promastigotes. The reproducibility of this system was largely dependent on parasite infectivity, and on BMM phagocytic capacity and 'health status'. Thus, the efficiency and the course of infection greatly varied, as was shown in three independent experiments (Table 1, 'treatment'). Nevertheless, a small percentage $(0.5-5 \%)$ of TUNEL-positive amastigote nuclei were detected in each experiment (Table 1 and Figure $4 C, D)$. These data suggest that cell death leading to nucleosomal DNA fragmentation also occurs in infected macrophages.

\section{DEVDase measurement in Leishmania}

Following data obtained with the DNA fragmentation and TUNEL assays, it was important to determine whether the pathway leading to Leishmania cell death was similar to that as described for higher eukaryotes. As caspases are key enzymes in the apoptotic pathways (and especially the abundant caspase-3 for apoptotic nuclease activation), the presence of caspase-like activity in the parasites was examined. Using a fluorometric caspase-3-7 assay, cleavage of the caspase-3-7 synthetic substrate (DEVD-AMC) was observed by $L$. major amastigote cytoplasmic extracts (Figure $5 A)$. This DEVDase activity could be inhibited by the addition
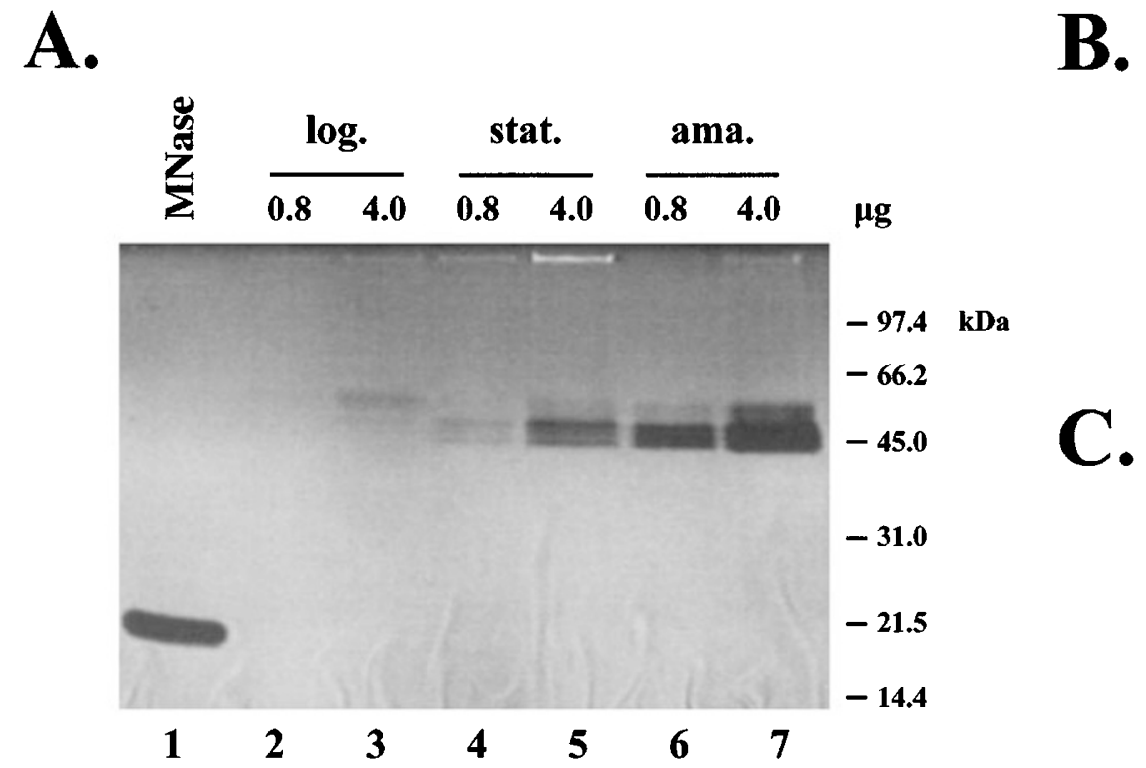
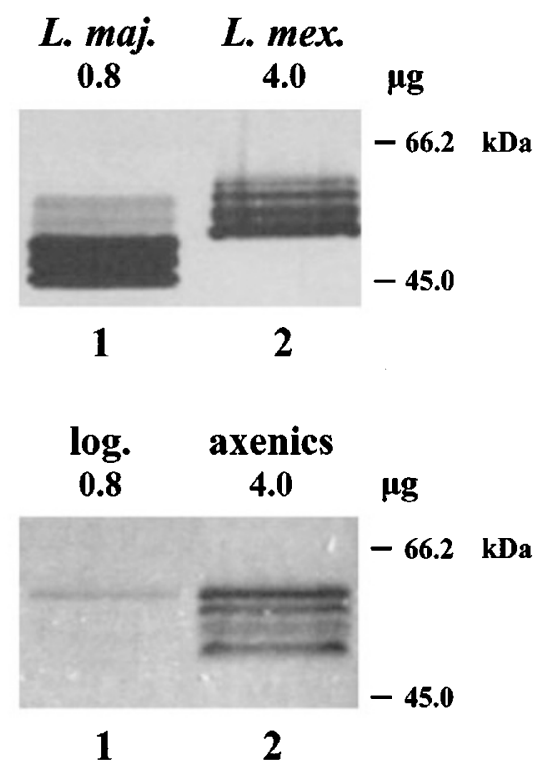

Figure 3 SDS-DNA-PAGE analysis of L. major and L. mexicana nuclei. The gels were incubated in $\mathrm{TEM}$ and $\mathrm{CaCl} 2(\mathbf{A})$, or in $\mathrm{TE}$ alone $(\mathbf{B}, \mathbf{C})$. (A) 0.8 and $4 \mu \mathrm{g}$ of L. major logarithmic (log.), stationary (stat.) phase promastigote and amastigote (ama.) nuclear proteins were loaded as indicated. Four mU (approximately 20 ng) of MNase was loaded as a positive control (lane 1). (B) 0.8 and $4 \mu \mathrm{g}$ of $L$. major amastigotes (lane 1 ) and $L$. mexicana axenics (10 days of differentiation) (lane 2) nuclear proteins were loaded respectively. (C) Four $\mu \mathrm{g}$ of $L$. mexicana logarithmic phase promastigotes (log.) and axenic (axenics, 10 days of differentiation) nuclear proteins were loaded 


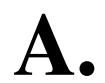

Phase
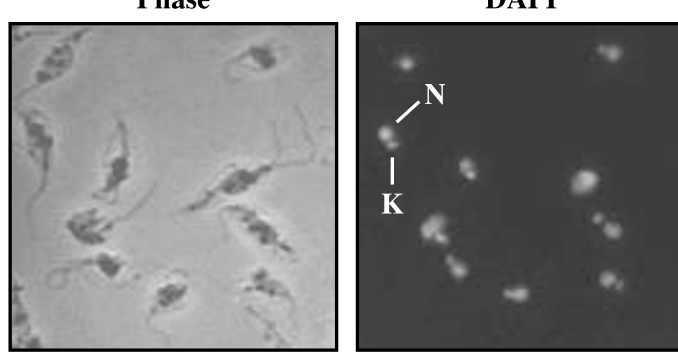

B.

DAPI

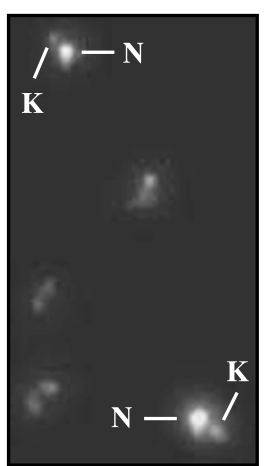

TUNEL

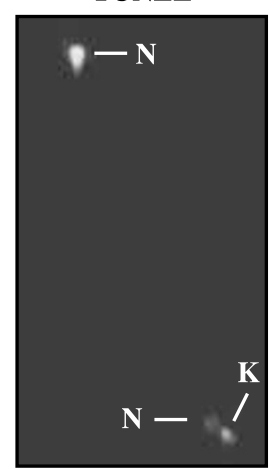

TUNEL

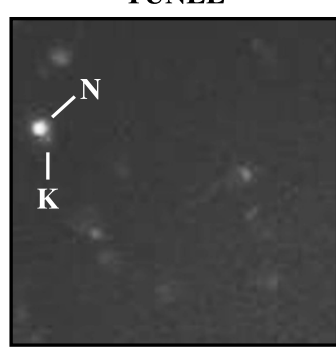

D.
DAPI

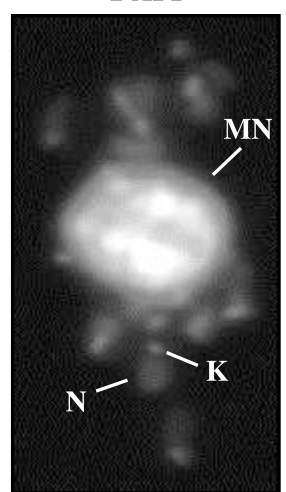

TUNEL

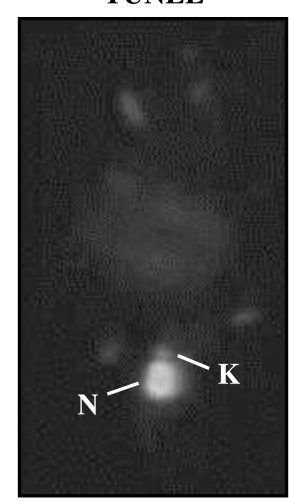

DAPI

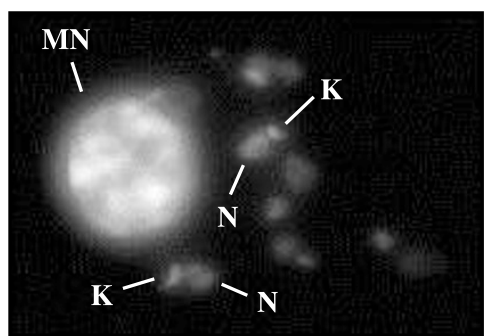

TUNEL

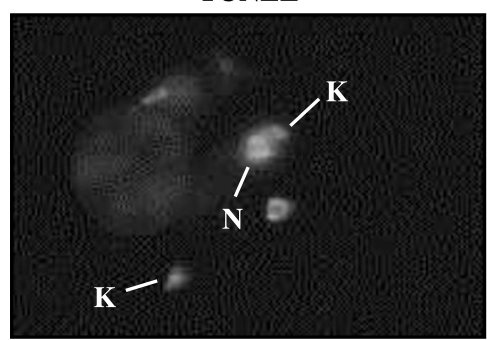

Figure 4 TUNEL-positive nuclei detected in Leishmania. TUNEL assay (TUNEL) and DAPI staining (DAPI) were performed as described in Materials and Methods. N: parasite nuclei. K: kinetoplast. MN: macrophage nuclei. (A) L. major stationary phase promastigotes. Phase, phase contrast alone. (B) L. mexicana axenics (10 days of differentiation). (C,D) BMMs in vitro infection (2 days) with L. major

Table 1 Increase in the percentage of TUNEL-positive amastigotes following macrophage stimulation. BMM were infected with $L$. major promastigotes and activated when indicated, by the addition of $\gamma$-IFN and LPS in the media. Number of parasites per macrophage and percentage of TUNEL-positive parasite nuclei were examined for 3 days in three independent experiments. $n p$, not performed

\begin{tabular}{|c|c|c|c|c|c|c|}
\hline \multirow[b]{2}{*}{ Experiment } & \multirow[b]{2}{*}{$\begin{array}{l}\gamma \text {-IFN/LPS } \\
\text { treatment }\end{array}$} & \multicolumn{2}{|c|}{1 day } & \multicolumn{2}{|c|}{2 days } & \multirow{2}{*}{$\begin{array}{c}3 \text { days } \\
\text { Parasite/BMM } \\
\text { (\% of killing) }\end{array}$} \\
\hline & & Parasite/BMM & $\begin{array}{c}\text { TUNEL-positive } \\
\text { nuclei }\end{array}$ & $\begin{array}{l}\text { Parasite/BMM } \\
\text { (\% of killing) }\end{array}$ & $\begin{array}{c}\text { TUNEL-positive } \\
\text { nuclei }\end{array}$ & \\
\hline \multirow[t]{2}{*}{1} & - & 3.1 & $5.2 \%$ & $2.4(-23 \%)$ & $2.1 \%$ & $1.1(-54 \%)$ \\
\hline & + & 3.6 & $11.6 \%$ & $1.7(-5.3 \%)$ & $40.0 \%$ & $0.1(-94 \%)$ \\
\hline \multirow[t]{2}{*}{2} & - & $\mathrm{np}$ & $\mathrm{np}$ & $5.6(n p)$ & $1.0 \%$ & $10.2(+82 \%)$ \\
\hline & + & $\mathrm{np}$ & $\mathrm{np}$ & $4.7(n p)$ & $60.0 \%$ & $2.4(-49 \%)$ \\
\hline \multirow[t]{2}{*}{3} & - & 1.8 & $0.7 \%$ & $1.5(-17 \%)$ & $0.5 \%$ & $1.3(-13 \%)$ \\
\hline & + & 2.3 & $4.1 \%$ & $1.0(-57 \%)$ & $5.0 \%$ & $0.1(-90 \%)$ \\
\hline
\end{tabular}

of the general caspase inhibitor z-VAD, similar to that observed with human apoptotic HEK293T cells (Figure 5A). Promastigote extracts did not show any activity. The amastigote DEVDase activity was not due to the presence of the abundant Leishmania cathepsin-like cysteine proteases (CPs), as the activity was not blocked by the addition of the CP specific inhibitor E-64 (Figure 5B). The activity was also not blocked by the presence of the serine and cysteine protease inhibitor leupeptin (data not shown). In addition, these inhibitors did not reduce the DEVDase activity of human apoptotic HEK293T cells (Figure 5B). However, as amasti- gotes were isolated from mouse lesions, it cannot be excluded that this apparent amastigote caspase activity was due to mouse caspase(s) contamination.

To resolve this issue, L. mexicana in vitro differentiated amastigotes ('axenics') were examined. L. mexicana axenic parasites, following 5 days of differentiation, showed no DEVDase activity, however, activity was present in $L$. mexicana amastigotes isolated from macrophages (Figure $5 \mathrm{C}$ ), similar to that observed for L. major parasites (Figure $5 \mathrm{~A}$ ). If the axenic parasites are cultured for 10 days in the differentiation conditions they form large aggregates and 

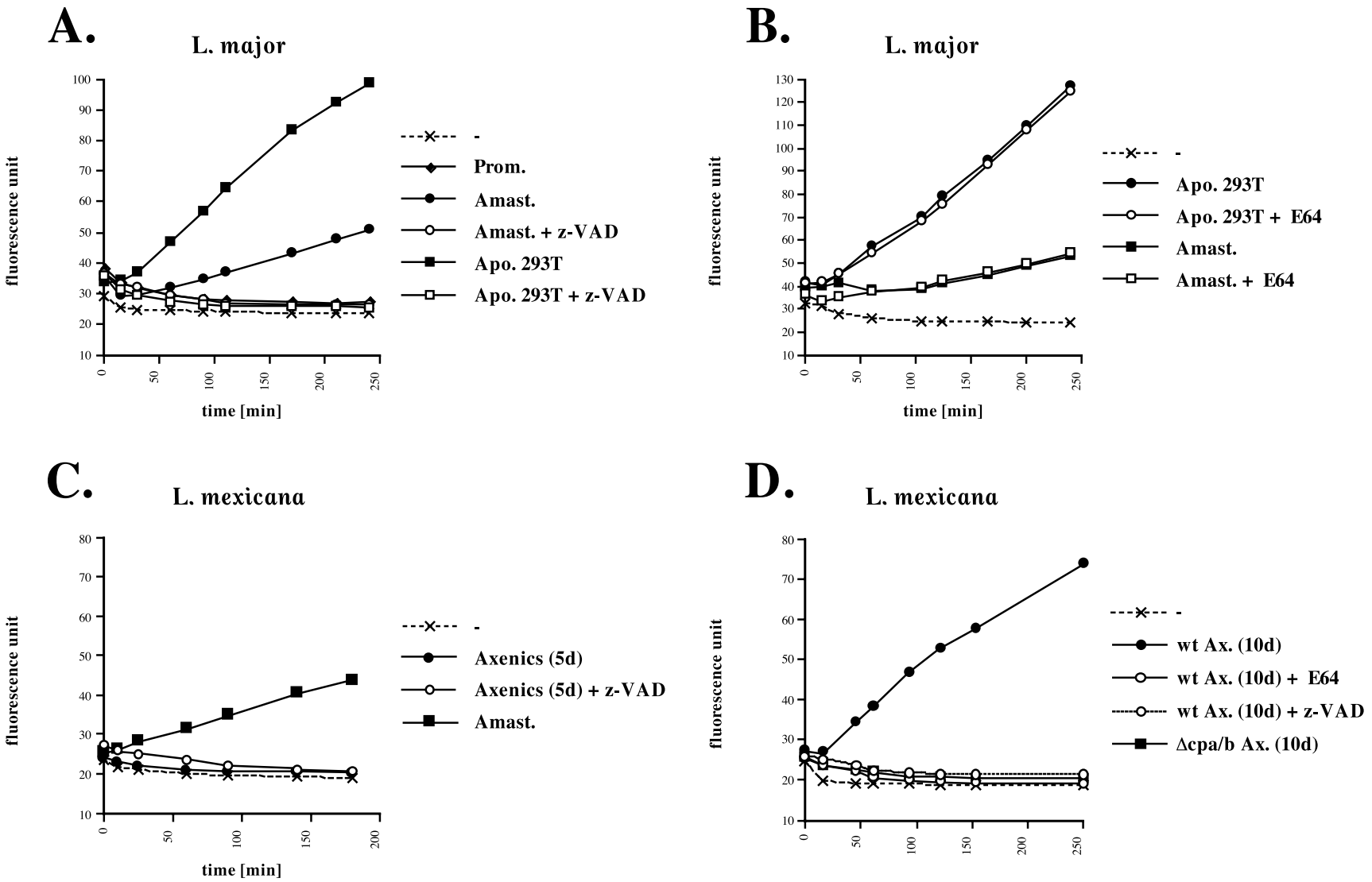

Figure 5 DEVDase activity detected in the amastigote stage of $L$. major $(\mathbf{A}, \mathbf{B})$ and $L$. mexicana (C,D). Cytoplasmic extracts of Leishmania (100 $\mu$ g) or apoptotic HEK293T cells $(40 \mu \mathrm{g})$ were incubated with $30 \mu \mathrm{M}$ of caspase-3-7 fluorogenic substrate DEVD-AMC. Z-VAD, leupeptin (data not shown) or E64 were added at a final concentration of $50 \mu \mathrm{M}, 100 \mu \mathrm{g} / \mathrm{ml}$ or $100 \mu \mathrm{M}$ respectively where indicated. Prom., L. major log. phase promastigotes. Amast., amastigote. Ax., L. mexicana axenics. Apo. HEK293T, apoptotic HEK293T cells. wt, L. mexicana wild-type. $\triangle \mathrm{cpa} / \mathrm{b}$, L. mexicana CPA and CPB null mutants. (A) Effect of z-VAD on the caspase activity of HEK293T cells and $L$. major amastigotes. (B) Effect of E64 on the caspase activity of HEK293T cells and $L$. major amastigotes. (C) Caspase activity of $L$. mexicana amastigotes and axenics (5 days of differentiation) in the presence or the absence of Z-VAD. (D) Caspase activity of $L$. mexicana wild-type and CPA and CPB null mutant axenics, following 10 days of differentiation in the presence or the absence of E64 or z-VAD

die. This is supported by the strong DNA degradation observed in such 'dying axenic parasites' (Figure 6, lane 1) as compared to 'healthy axenics' (following 5 days of differentiation), where DNA laddering was much weaker (Figure 1A, lane 4). In 10 days axenics, DEVDase activity was detected (Figure 5D). This activity was inhibited by E64 , suggesting that it is due to cathepsin-like cysteine proteases and not caspases, which are insensitive to the inhibitor (Figure 5B) ${ }^{38}$ In 10 days axenic parasites, the DEVDase activity is also inhibited by z-VAD (Figure $5 D$ ). The finding that the $C P A$ and $C P B$ double null mutant $(\triangle c p a / c p b)^{39}$ lacked DEVDase activity also supports the concept that the cleavage of DEVD substrate in the 10 days axenic sample is due to CPA or CPB activity (Figure $5 \mathrm{D})$. Despite this difference, nuclei from both $\mathrm{CP}$ double knockout mutants and wild-type parasites showed no major difference in terms of DNA fragmentation (Figure 6).

To investigate if DEVDase activity detected in the amastigote extract was due to contamination of preparations with mouse proteins, immunoblot analysis was performed. Comparable amounts, in regard to DEVDase activity, of A20 apoptotic mouse cells and amastigote cytoplasmic extracts were used for caspase-3 and 7 immunodetection. Active caspase- 3 was detected in the A20 apoptotic cell positive control as evidenced by the presence of an $18 \mathrm{kDa}$ protein (Figure 7A, lane 1), but not in the amastigote extract (Figure 7A, lanes 2-5). However, the active form of caspase-7, which also has DEVDase activity, was recognised by a specific antibody in amastigote extracts (Figure 7B, lanes 5-8), and also in the A20 control (Figure 7B, lanes 1-4). The absence of mouse actin in the parasite extract served as a final control for general mouse protein contamination (Figure 7C, lane 2). These results indicate that the DEVDase activity detected in mouse lesion-isolated amastigotes was likely to be due to the presence of mouse caspase-7 rather than a Leishmania caspase.

\section{Induction of cell death in culture}

The induction of cell death in Leishmania was first examined by the removal of serum from the culture media. The absence of serum caused a stress situation for the parasites, as observed by the increase in nucleosomal DNA fragmentation 


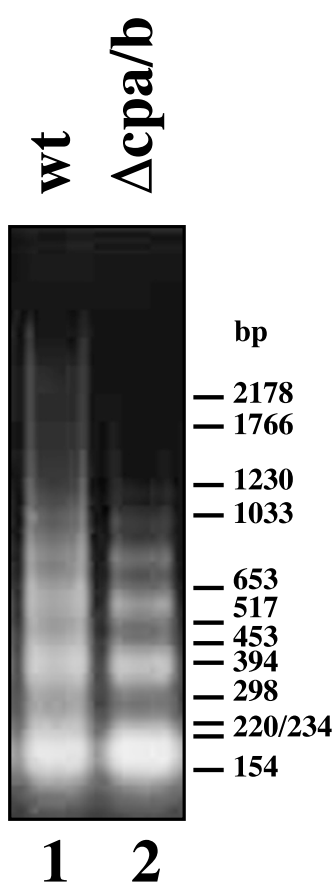

Figure 6 DNA degradation of $L$. mexicana wild-type and $\Delta \mathrm{cpa} / \mathrm{b}$ axenics (10 days of differentiation). Genomic DNA of wild-type (wt) and CPA/B null mutants $(\Delta \mathrm{cpa} / \mathrm{b}) L$. mexicana axenic parasites were extracted, precipitated and loaded on a $2 \%$ agarose gel

in stationary phase promastigotes (Figure 8A) and axenics (data not shown). However, this increase in fragmentation was slow, as it took 2 days after serum removal to be efficient (Figure 8A).

In the search for a more efficient cell death inducer, a short heat-shock treatment $\left(10 \mathrm{~min}\right.$ at $\left.55^{\circ} \mathrm{C}\right)$, which was recently described to provoke $\mathrm{PCD}$ in plants, ${ }^{40}$ was investigated. The heat-shock method was tested on logarithmic phase promastigotes, which normally do not show DNA degradation (Figure 8B, first lane). No effect was detected $1 \mathrm{~h}$ following heat-shock, however, nucleosomal fragmentation was already apparent at $4 \mathrm{~h}$ following heat-shock (Figure 8B). This effect was supported by a high percentage (about $30 \%$ ) of parasites showing TUNELpositive staining of their nuclei (Figure 9). Preincubation of the parasite cultures with the cathepsin and caspase inhibitors E-64 and Z-VAD prior to heat-shock did not decrease the level of DNA fragmentation significantly (data not shown).

It was of interest to examine the effect of Nitric Oxide (NO) in culture, as it is one of the most significant mechanisms whereby macrophages kill the parasites in vivo. ${ }^{41}$ An in vitro system designed to directly produce NO in promastigote cultures was used. ${ }^{41} \mathrm{NO}$ killing of logarithmic phase promastigotes also lead to DNA fragmentation into oligonucleosomes (Figure $8 \mathrm{C}$ ). This effect of $\mathrm{NO}$ was confirmed in BMM in vitro infection experiments. Following macrophage stimulation by gammainterferon $(\gamma$-IFN) and lipopolysaccharide (LPS), which induces NO production and consequent parasite killing, the amount of TUNEL-positive amastigotes was at least doubled in comparison to non-activated BMM (Table 1). To reiterate, the percentage of TUNEL-positive parasites strongly varied between different experiments, but the increase of this percentage due to NO production was always present. These data suggest that $\mathrm{NO}$ also kills by a process leading to nucleosomal fragmentation, TUNEL staining and probable associated nuclease activity. Killing by NO production was used for ultrastructural analysis of the nucleus during the death process. As shown in Figure 10 , condensation of the chromatin can be observed after $1 \mathrm{~h}$ of incubation in NO. Fragmentation of the nucleus occurs in cells that do not show any evidence of membrane leakage, suggesting that TUNEL positive cells and consequently DNA fragmentation occurs early in the death process and not as a post-mortem event due to a necrotic phenomenon. Other morphological changes such as mitochondrial swelling and cytoplasmic vacuolation can be observed.

Finally, it was necessary to analyze the effect of necrosis on genomic DNA. To provoke necrosis, parasites were incubated in a low amount of TX-100 detergent, similar to that described for mammalian systems. ${ }^{42}$ No nucleosome monomer is detected in the non-treated sample (Figure 8D). Nucleosomal fragmentation was visible following only $1 \mathrm{~h}$ of treatment (Figure 8D). After $2 \mathrm{~h}$ of treatment, a clear increase in the amount of the nucleosome monomer is visible. As previously observed, the kinetoplast minicircle DNA (ca 650 bp) is visible in most of the samples.

\section{Discussion}

In this study, oligonucleosomal DNA fragmentation was observed in the infective stages of the protozoan parasite Leishmania, particularly in the amastigote form. Oligonucleosomal DNA fragmentation represents a late event of this suicidal pathway leading to the passive release of DNA in the cytoplasm of apoptotic cells.

The degradation pattern observed in Leishmania correlates with the pattern obtained following chromatin digestion with MNase, indicating that the degradation results from the action of an endogenous site-unspecific endonuclease (like MNase), which cleaves in the internucleosomal regions of the chromatin. In association with DNA fragmentation, the presence of endonuclease activity, detection of TUNELpositive nuclei and identification of nucleases of approximately $45-59 \mathrm{kDa}$, which are likely to be responsible for this degradation, were demonstrated. Classical cofactors of nucleases, such as $\mathrm{Ca}^{2+}$ or $\mathrm{Mg}^{2+}$, were not required for the activity of these leishmanial nucleases, however the presence of $\mathrm{Zn}^{2+}$ had an inhibitory effect. $\mathrm{Zn}^{2+}$-inhibition of apoptotic endonuclease activities was previously described in mammals. ${ }^{43-46}$ In this study, it was also shown that $\mathrm{Zn}^{2+}$ was able to block MNase activity. None of the previous reports clearly demonstrate that $\mathrm{Zn}^{2+}$ directly inhibits these endonuclease activities. It is possible that $\mathrm{Zn}^{2+}$ acts on chromatin structure and the consequent accession of the chromatin to any endonuclease, rather than by directly inhibiting the activity of the enzyme, as previously proposed. ${ }^{47}$ 

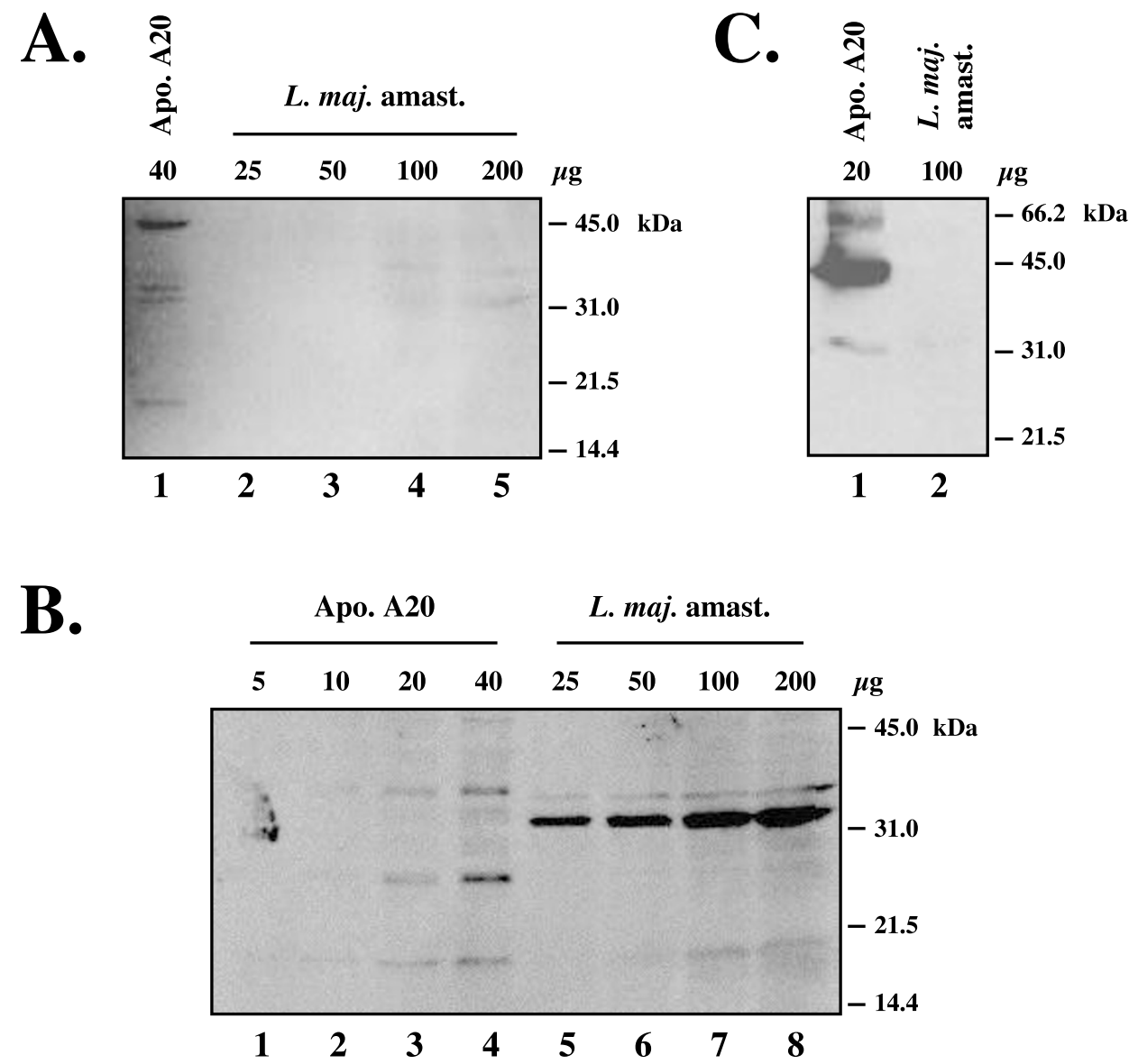

Figure 7 Presence of mouse caspase-7 in amastigote extracts. Presence of mouse caspase-3 (A), caspase-7 (B) and actin (C) were examined in amastigote cytoplasmic extracts and compared to apoptotic mouse A20 cells. DEVDase activity was measured in both extracts (data not shown) and comparable amounts (in terms of activity) were loaded on a $12.5 \%$ acrylamide gel. Five to $40 \mu \mathrm{g}$ of protein was loaded for A20 extracts, and 25 to $200 \mu \mathrm{g}$ for amastigote extracts as indicated ( $5 \mu \mathrm{g}$ of A20 having the same DEVDase activity as $25 \mu \mathrm{g}$ of amastigote). Full length (inactive) and cleaved (active) forms of caspases are shown

The Leishmania nucleases that were detected in our assays migrate with higher molecular masses than most of the apoptotic nucleases described to date, such as CAD or DNase I and II. ${ }^{48}$ There is only one report describing probable human apoptotic nucleases with similar sizes $(42-50 \mathrm{kDa})$, but with different properties $\left(\mathrm{Ca}^{2+} / \mathrm{Mg}^{2+}\right.$-dependant nucleases $) .{ }^{49}$ Helicases have comparable molecular weights, and some might be implicated in the apoptotic process. ${ }^{50}$ Interestingly, in the ciliates Tetrahymena and Stylonychia, two homologous nucleases (Pdd1p and Spdd1p, respectively), with a size of $54 \mathrm{kDa}$, were described as being implicated in the apoptotic-like degradation of the nuclei. ${ }^{8,30}$ To date, there has been no description of such nucleases in trypanosomatids. The only nuclease with similar size (although a bit smaller, $43 \mathrm{kDa}$ ) that was described in Leishmania is the surface $3^{\prime}$-nucleotidase/nuclease. ${ }^{51}$ However, a direct comparison of the molecular masses of the different nucleases is difficult since in our assays, the samples were not heat-treated in order to maintain nuclease activity in the SDS-DNA-PAGE system. Cloning and characterization of the Leishmania nucleases should help solve this issue.

TUNEL-positive parasite nuclei were not only detected in dying promastigotes, axenics and amastigotes, but also during in vitro infection. The percentage of positive parasites was low, but in accordance with the fact that most of the parasites are normally not dying under such conditions. Nevertheless, this result is of importance, as it supports the previous nuclease and DNA degradation observations in a more natural situation, that is, during macrophage infection. More precisely, it suggests that the apoptosis-like features observed were not only found in in vitro cultured parasites, but also in amastigotes purified from mouse lesions.

In mammals caspases- 3 and -7 have DEVDase activity. Such activity was not found in either stationary phase promastigotes or in 5 day axenic cultures of Leishmania, indicating that the activity is not required for nucleosomal DNA degradation. This was further supported when addition of the caspase inhibitor z-VAD in promastigote and axenic cultures had no effect on DNA fragmentation 

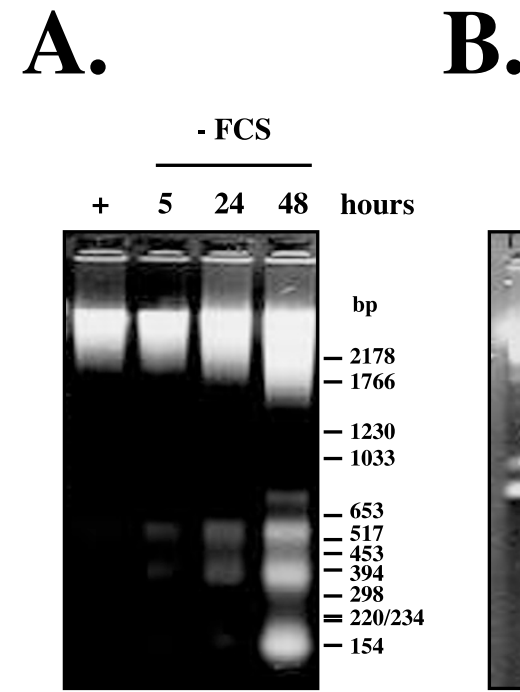

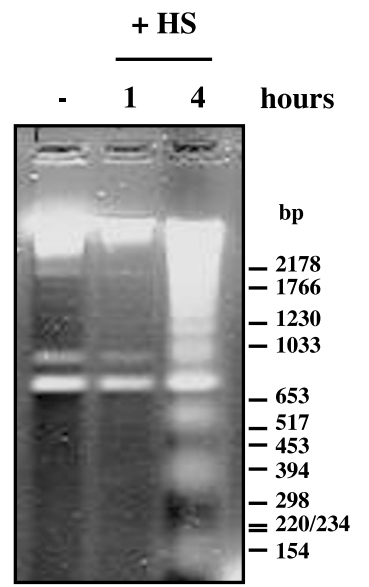

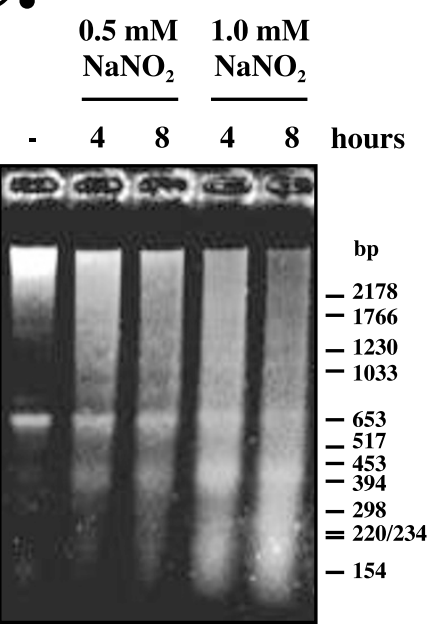

D.

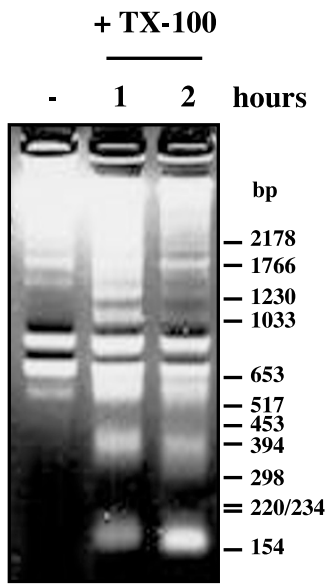

Figure 8 Induction of cell death in L. major promastigotes. Promastigote DNA was extracted and loaded on a $2 \%$ agarose gel. (In (A), DNA was extracted from intact nuclei and in (B,C) directly from NP-40 pellet refer to Material and Methods). All parasites were maintained in culture for the same period. Lane 1 ( - , in B,D): no treatment. (A) Serum removal. Stationary phase promastigotes were grown in the presence $(+)$ or absence of foetal calf serum (FCS) for the final 5,24 or $48 \mathrm{~h}$ in culture, as indicated. (B) Heat-shock. Logarithmic phase promastigotes were incubated for $10 \mathrm{~min}$ at $55^{\circ} \mathrm{C}$, and then reincubated at $26^{\circ} \mathrm{C}$ for a further 1 or $4 \mathrm{~h}$. (C) NO killing. Logarithmic phase promastigotes were incubated with 0.5 or $1 \mathrm{mM} \mathrm{NaNO}_{2}$ for 4 or $8 \mathrm{~h}$ at pH 5.5. (D) TX-100 addition. Logarithmic phase promastigotes were incubated with $0.01 \%$ TX-100 for 1 or $2 \mathrm{~h}$. Similarly to Figure 1, kinetoplast DNA is visible in certain lanes
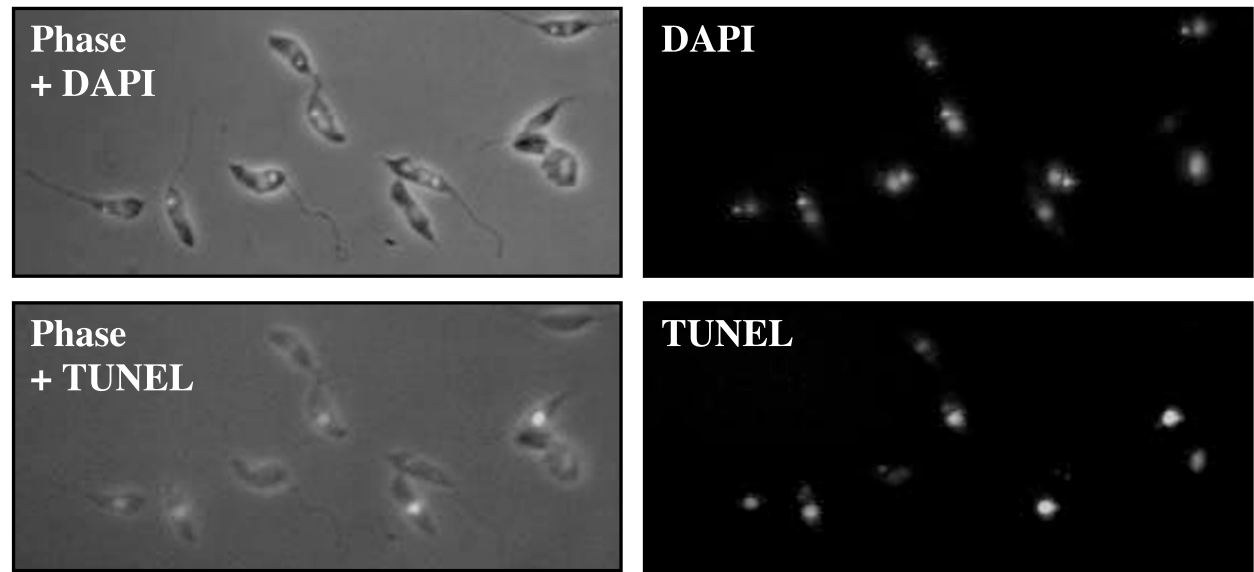

Figure 9 TUNEL-positive parasites following heat-shock. TUNEL assay (TUNEL) and DAPI staining (DAPI) were performed as described in Materials and Methods on logarithmic phase promastigotes, $4 \mathrm{~h}$ following heat-shock treatment $\left(10 \mathrm{~min}\right.$ at $\left.55^{\circ} \mathrm{C}\right)$. Phase, phase contrast

(data not shown). In mouse lesion purified amastigotes, mouse caspase-7 was detected, and is likely to be responsible for the DEVDase activity observed. Its presence does not seem to be due to mouse protein contamination, which has been observed previously, ${ }^{52}$ as neither mouse caspase-3 nor actin was detected in the purified amastigotes. Interestingly, in mammals it was proposed that active caspase-7 is translocated to the mitochondria and the microsomes following Fas stimulation. ${ }^{53}$ Consequently, it is possible that, during Leishmania infection, active caspase- 7 has access to parasites present in the macrophage phagolysosomes, thus explaining the results obtained in this study. Whether or not caspase-7 has any role in Leishmania cell death has yet to be determined.

The Leishmania cysteine protease $\mathrm{CPA}$ or $\mathrm{CPB}$, which belong to the papain-like class of cysteine, ${ }^{54}$ could be responsible for the DEVDase activity detected in axenics, as revealed by the inhibition observed with the use of the CPs inhibitor E-64 and the analysis of wild-type and $\Delta c p a /$ $c p b$ double null mutants. However, the known substrates of CPB are very different from DEVD, ${ }^{55,56}$ and other work has shown directly that DEVD is a poor substrate for recombinant CPB (SJ Sanderson, JC Mottram and GH Coombs, unpublished). It is thus possible that CPA, and not $\mathrm{CPB}$, is responsible for the majority of the DEVDase activity 

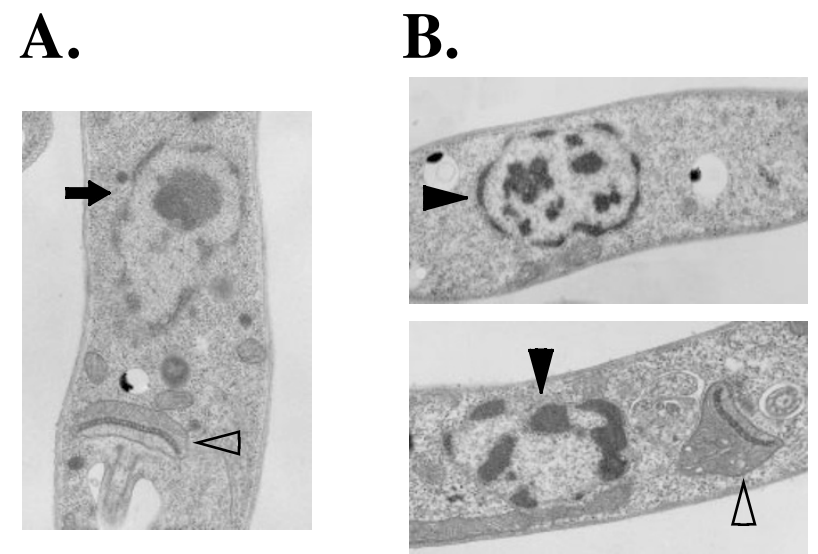

Figure 10 Ultrastructural analysis of $L$. major parasites in the absence or in the presence of NO. Parasites were incubated in the absence $(\mathbf{A})$ or in the presence of NO for $1 \mathrm{~h} \mathrm{(B).} \mathrm{Magnification} \mathrm{8'900X.} \mathrm{Arrow} \mathrm{points} \mathrm{to} \mathrm{intact} \mathrm{nuclei.}$ Solid arrowheads point to condensed nuclei and empty arrowheads point to kinetoplasts

in axenics. Further analysis of $\Delta c p a$ and $\Delta c p b$ single null mutants should provide definitive answer to this question. Leishmania CPs are abundantly expressed at the amastigote stage of the parasite, and have been shown to be virulence determinants. ${ }^{39,57}$ Indeed, specific inhibition of cysteine proteases in situ using cell permeant diazomethylketones (Z-FA-DMK) reduced the infectivity of promastigotes Leishmania to macrophages by $80 \%{ }^{58}$

Interestingly, mammalian cathepsins were observed to participate in the apoptotic cascade in certain systems, ${ }^{38,59-61}$ and the CP inhibitor E-64 was shown to block Peridinium PCD. ${ }^{18}$ Nevertheless, in the work described here, the absence of CPA and CPB did not have a strong effect on the nucleosomal fragmentation of axenics. It could, however, be interesting to analyze if CPC, a cathepsin B-like cysteine protease described in Leishmania, ${ }^{62}$ could have a role in this process.

In the search for inducers of cell death in Leishmania, it was observed that the removal of serum from the culture medium (similar to the mammalian situation) fulfilled this requirement. Other more efficient inducers were also identified. Heat-shock (as described in plants), ${ }^{40} \mathrm{NO}$ killing and finally detergent treatment, which normally mimics necrosis in mammals, all lead to oligonucleosomal DNA fragmentation. Thus, the death process in Leishmania could lead, in all cases, to DNA fragmentation into oligonucleosomes, and may be independent of a programmed and active pathway. Furthermore, when parasites are killed by NO, cytoplasmic vacuolation and mitochondrial swelling are observed. These morphological changes have been associated to necrosis and to an alternative nonapoptotic form of programmed cell death, paraptosis. ${ }^{63}$ The observations in this work, together with other previous reports that support the existence of PCD in trypanosomatids based on morphological characteristics of mammalian apoptosis, ${ }^{5,21-23,25}$ must be interpreted with caution.

Interestingly, two recent reports show that Leishmania treated with antimonials or hydrogen peroxide lead to some oligonucleosomal DNA fragmentation and TUNEL-staining in Leishmania. ${ }^{64,65}$ However, the implicated pathways could differ in these two systems, since their first results (using different protease inhibitors) suggest that caspase, calpain and CPs are not involved in the process of antimonial killing, ${ }^{65}$ while caspase-like activity appeared to be important in hydrogen peroxide killing. ${ }^{64}$ Further work will obviously be necessary to precisely dissect the cell death pathway(s) in Leishmania and to determine the contribution of various proteases.

We propose that the induction of cell death in Leishmania may function via the lysosome, thus provoking the rupture of the fragile membrane and consequent release of lysosomal enzymes, such as nucleases, into the cytoplasm and finally into the nuclei of the dying parasite. Because of the very low amount of chromatin compaction in trypanosomatids ${ }^{66}$ in contrast to mammals, the release of these lysosomal nucleases could lead to strong and fast DNA degradation into oligonucleosomes. In this hypothesis, other lysosomal enzymes, and especially the abundant $\mathrm{CPs}^{54}$ would be released into the cytoplasm. CPs could thus, on a mass scale, degrade cytoplasmic and nuclear proteins. Degradation of chromatin-associated proteins by CPs could, in particular, explain why the DNA fragmentation observed in wild-type axenics appeared more like a smear than that observed in wild-type promastigotes, or axenic $\Delta c p a / c p b$ double null mutants (both contain a lower amount of CPs as compared to wild-type axenics). This hypothesis might be true for different stress stimuli, such as those tested in this study and possibly others, and also for 'natural' death situations occurring in long-term, stationary cultures maintained in the same growth medium.

This proposed model would thus give an additional role for CPs in Leishmania, and provide one possible explanation for their striking abundance. In this model, CPs would degrade endogenous proteins following killing during infection. This would lead, by the additional action of macrophage cathepsins, to strong antigen processing in shorter fragments than usually produced by mammalian cathepsins alone. This in turn could diminish antigen presentation at the macrophage surface, which would aid survival and proliferation of the remaining parasites. The implication of this model could be of primary importance in early infection, where a significant proportion of promastigotes fail to differentiate and infect efficiently. Indeed, such a model is supported by previous reports demonstrating that CPB deficient parasites are less able to survive in mice macrophages than wild-type cells and cause a switch in the immune response inducing a protective phenotype. ${ }^{39,67}$

Generally, the existence of a specific cell death mechanism might be useful in the host to avoid an inflammatory response following stress-induced death of amastigotes and promastigotes.

Taken together, our results demonstrate that the death mechanism in Leishmania, and perhaps trypanosomatids in general, is quite different to mammals. However it is not possible to exclude the existence of PCD in these organisms. A more precise description of unicellular death would be informative in the understanding of how cell death has evolved in higher eukaryotes. From the data presented in this 
work, we propose that cell death in Leishmania is not effected by classical apoptosis mechanisms. Rather, the mechanism of cell death could have developed in such a way that parasite killing during infection does not provoke an immune response in the host, thus facilitating further infection by the remaining parasites. The further study of the Leishmania death process will be of significance in the greater understanding of the interaction between the parasite and its host and also cell death mechanisms in general.

\section{Materials and Methods}

\section{Parasites}

Leishmania major MRHO/IR/75 and L. mexicana MNYC/BZ/62/M379 wild-type and $\Delta c p a / c p b$ mutant ${ }^{39}$ promastigotes were grown at $26^{\circ} \mathrm{C}$ in Schneider's Drosophila medium (Bioconcept-Amimed), supplemented with $10 \%$ heat inactivated foetal calf serum (FCS, Seromed), $1.8 \mathrm{mg} /$ $\mathrm{ml}$ glutamine and $10 \mu \mathrm{g} / \mathrm{ml}$ gentamicin. Amastigotes were obtained from lesions in Swiss nude mice. ${ }^{68}$ L. mexicana in vitro differentiated amastigote (axenic) parasites were obtained from stationary phase promastigotes diluted 10 times in the differentiation medium (Schneider's Drosophila Medium equilibrated at $\mathrm{pH} 5.5$ with $\mathrm{HCl}$ and complemented with $20 \%$ FCS, $1.8 \mathrm{mg} / \mathrm{ml}$ glutamine and $10 \mu \mathrm{g} / \mathrm{ml}$ gentamicin), and incubated for 5 days at $33^{\circ} \mathrm{C} .{ }^{39}$ Where indicated, parasites were maintained for a longer period in culture (usually 10 days).

\section{DNA fragmentation and MNase digestion assays}

Intact nuclei were prepared based on a modified protocol described previously for Trypanosoma brucei. ${ }^{69}$ Briefly, following lysis of the cells in a cavitation chamber (under 23 bars of nitrogen), the pellet was washed, resuspended in the nuclei storage solution and stored at $-70^{\circ} \mathrm{C}$. Nuclei were incubated at $30^{\circ} \mathrm{C}$ with or without $5 \mathrm{mU}$ of MNase per $\mu \mathrm{g}$ of DNA (based on OD at $260 \mathrm{~nm}$ ) in $\mathrm{pH} 7.4$ nuclei storage buffer (340 mM sacharose, $0.1 \mathrm{mM}$ EDTA, $60 \mathrm{mM} \mathrm{KCl,} 15 \mathrm{mM} \mathrm{NaCl}$, $0.15 \mathrm{mM}$ spermin, $0.15 \mathrm{mM}$ spermidin, $15 \mathrm{mM}$ Tris) supplemented with $1 \mathrm{mM} \mathrm{CaCl}_{2}{ }^{69}$ Digestion was blocked by the addition of $2.5 \mathrm{mM}$ EDTA. DNA was extracted with phenol/chloroform and precipitated before loading on a $2 \%$ agarose gel. For cell death induction (except Figure $8 \mathrm{~A}$ ), genomic DNA was directly extracted from the NP-40 nuclei pellet $^{70}$ resuspended in nuclei storage buffer.

\section{Gel nuclease activity assay (SDS - DNA-PAGE)}

Direct nuclease activity was observed using the SDS-DNA-PAGE technique as previously described. ${ }^{45}$ Briefly, denatured herring sperm DNA was added in a $12.5 \%$ acrylamide separating gel. Following migration of the samples, the gel was washed in TEM $(50 \mathrm{mM}$ Tris, $1 \mathrm{mM}$ EDTA, $2 \mathrm{mM} \mathrm{MgCl}_{2}$ ) overnight, and nuclease activity was visualised by incubation at $37^{\circ} \mathrm{C}$ in TEM with $1 \mathrm{mg} / \mathrm{ml}$ ethidium bromide and $2 \mathrm{mM} \mathrm{CaCl}_{2}$ for MNase activity $\left(\mathrm{Ca}^{2+}\right.$-dependent). For the parasitic nuclease activity assay, gels were usually incubated in $\mathrm{TE}$ and $\mathrm{EtBr}$ alone (without the addition of salt; the activity does not depend on the presence of $\mathrm{Ca}^{2+}$ or $\mathrm{Mg}^{2+}$ ).

\section{DEVDase activity assay and immunoblotting}

The caspase-3-7 substrate Ac-DEVD-AMC (Alexis ${ }^{\circledR}$ ) was used throughout. Rambo transfected human HEK293T cells ${ }^{71}$ and FasL stimulated (10 ng/ml for $20 \mathrm{~h}$ ) A20 mouse lymphoma cells were used as positive controls. Cytoplasmic extracts (NP-40 supernatant with $1 \mathrm{mM}$ PMSF, $2 \mu \mathrm{g} / \mathrm{ml}$ leupeptin and $2 \mu \mathrm{g} / \mathrm{ml}$ pepstatin A, as described in $^{72}$ for mammalian cells and ${ }^{70}$ for parasites) were incubated in CHAPS buffer ${ }^{72}$ containing $30 \mu \mathrm{M}$ Ac-DEVD-AMC. Fluorescence emission at $460 \mathrm{~nm}$ (excitation at $355 \mathrm{~nm}$ ) was measured with a Fluoroskan II apparatus.

Immunoblotting was performed as previously described ${ }^{70}$ using the following antibodies (1:1000 dilutions): anti-cleaved caspase-3 rabbit polyclonal antibody (New England Biolabs, 9661), anti-caspase7 rabbit polyclonal antibody (New England Biolabs, 9492) and antiactin mouse monoclonal antibody (Bio-Science, 010056).

\section{BMM in vitro infection and TUNEL assay}

BMM were prepared, cultured and infected with $L$. major promastigotes as previously described. ${ }^{73}$ Briefly, $10^{5} \mathrm{BMM}$ were distributed in 24-well cell culture plates, each well containing a round sterile glass coverslip, before infection (5 parasites per BMM). Where indicated, BMM were stimulated with $50 \mathrm{U} \mathrm{ml}^{-1} \gamma$-IFN and $10 \mathrm{ng} \mathrm{ml}^{-1}$ LPS. TUNEL assay ('Apoptosis detection system, Fluorescein', Promega) was performed as recommended by the manufacturer. TUNEL was directly performed on glass slides covered with BMM for in vitro infection studies. Parasites alone were first fixed for $25 \mathrm{~min}$ at $4^{\circ} \mathrm{C}$ in a solution containing $4 \%$ paraformaldehyde and then spread on polylysine coated glass slides for 5 min before performing the TUNEL assay.

\section{NO treatment and transmission electron microscopy}

Promastigote parasites are resuspended into HBSS $1 \times$ (Hanks' balanced salt without phenol red, (Gibco BRL \#14065-49) with $\mathrm{NaHCO}_{3}(350 \mathrm{mg} / \mathrm{l}) \mathrm{pH}$. Parasite are incubated for $1 \mathrm{~h}$ in the absence or in the presence of $1 \mathrm{mM} \mathrm{NaNO} 2$ (Merck, Catalog No. 6549), washed twice in PBS $1 \times$, extracted with lysis buffer $(0.14 \mathrm{M}$ $\mathrm{NaCl}, 1.5 \mathrm{mM} \mathrm{MgCl}_{2}, 10 \mathrm{mM}$ Tris $\mathrm{HCl} \mathrm{pH} \mathrm{8,0.5 \%} \mathrm{NP40)} \mathrm{on} \mathrm{ice} \mathrm{and}$ then centrifuged at $9000 \times \mathrm{g}$. Phenol/chloroform extraction is performed twice on the pellet. The genomic DNA is treated with RNase (DNase free RNase, Roche) and visualised on a $2 \%$ agarose gel stained with ethidium bromide.

For transmission electron microscopy, control parasites and parasites exposed to $\mathrm{NO}$ for $1 \mathrm{~h}$ were fixed $\mathrm{ON}$ at $4^{\circ} \mathrm{C}$ in $1.25 \%$ glutaraldehyde in $0.1 \mathrm{M}$ cacodylate buffer followed by $1 \mathrm{~h}$ incubation in $2.45 \%$ glutaraldehyde, dehydrated with ethanol at room temperature and immersed in a 1:1 mixture of ethanol $100 \%$ and EPON. The samples were embedded in Epon by polymerisation at $60^{\circ} \mathrm{C}$ for 2 days. Ultrastructure analysis was performed on a Philips EM 410 electron microscope.

\section{Acknowledgements}

The authors would like to thank Adriana Ransijn for BMM in vitro infection experiments and other valuable technical advice. We thank the group of Viesturs Simanis for their support in microscopy, and the group of Jürg Tschopp for helpful and critical discussions. Slavica Masina and Simon Lillico are thanked for careful reading of the manuscript. This study was supported by a FNRS grant (No. 3100-59450.99). Jeremy C Mottram is a Medical Research Council Senior Research Fellow. 


\section{References}

1. Jacobson MD, Weil M and Raff MC (1997) Programmed cell death in animal development. Cell 88: 347-354

2. Greil R, Egle A and Villunger A (1998) On the role and significance of Fas (Apo-1) CD95) ligand (FasL) expression in immune privileged tissues and cancer cells using multiple myeloma as a model. Leuk. Lymphoma 31: 477-490

3. Evan G and Littlewood T (1998) A matter of life and cell death. Science 281: $1317-1322$

4. Welburn SC, Barcinski MA and Williams GT (1997) Programmed cell death in Trypanosomatids. Parasitol. Today 13: 22-26

5. Ameisen JC. (1996) The origin of programmed cell death [see comments]. Science 272: 1278-1279

6. Christensen ST, Leick V, Rasmussen L and Wheatley DN (1998) Signaling in unicellular eukaryotes. Int. Rev. Cytol. 177: 181-253

7. Davis MC, Ward JG, Herrick G and Allis CD (1992) Programmed nuclear death: apoptotic-like degradation of specific nuclei in conjugating Tetrahymena. Dev. Biol. 154: 419-432

8. Madireddi MT, Coyne RS, Smothers JF, Mickey KM, Yao MC and Allis CD (1996) Pdd1p, a novel chromodomain-containing protein, links heterochromatin assembly and DNA elimination in Tetrahymena. Cell 87: 75-84

9. Mpoke S and Wolfe J (1996) DNA digestion and chromatin condensation during nuclear death in Tetrahymena. Exp. Cell. Res. 225: 357-365

10. Mpoke SS and Wolfe J(1997) Differential staining of apoptotic nuclei in living cells: application to macronuclear elimination in Tetrahymena. J. Histochem. Cytochem. 45: 675-683

11. Christensen ST, Mottram JC, Staarup EM, Kristiansen K, Wheatley DN and Rasmussen L (1998) Staurosporine-induced cell death in Tetrahymena thermophila has mixed characteristics of both apoptotic and autophagic degeneration. Curr. Biol. Int. 22: 591-598

12. Kovacs P, Hegyesi H, Kohidai L, Nemes P and Csaba G (1999) Effect of C2 ceramide on the inositol phospholipid metabolism (uptake of $32 \mathrm{P}, 3 \mathrm{H}$-serine and $3 \mathrm{H}$-palmitic acid) and apoptosis-related morphological changes in Tetrahymena. Comp. Biochem. Physiol. C Pharmacol. Toxicol. Endocrinol. 122: 215-224

13. Cornillon S, Foa C, Davoust J, Buonavista N, Gross JD and Golstein P (1994) Programmed cell death in Dictyostelium. J. Cell. Sci. 107: 2691-2704

14. Cornillon S, Olie RA and Golstein P (1998) An insertional mutagenesis approach to Dictyostelium cell death. Cell Death Differ. 5: 416-425

15. Schaap P, Nebl T and Fisher PR (1996) A slow sustained increase in cytosolic $\mathrm{Ca} 2+$ levels mediates stalk gene induction by differentiation inducing factor in Dictyostelium. EMBO J. 15: 5177-5183

16. Olie RA, Durrieu F, Cornillon S, Loughran G, Gross J, Earnshaw WC and Golstein P (1998) Apparent caspase independence of programmed cell death in Dictyostelium. Curr. Biol. 8: 955-958

17. Verkerke-van Wijk I, Brandt R, Bosman L and Schaap P (1998) Two distinct signaling pathways mediate DIF induction of prestalk gene expression in Dictyostelium. Exp. Cell. Res. 245: 179-185

18. Vardi A, Berman-Frank I, Rozenberg T, Hadas O, Kaplan A and Levine A (1999) Programmed cell death of the dinoflagellate Peridinium gatunense is mediated by $\mathrm{CO}(2)$ limitation and oxidative stress. Curr. Biol. 9: 1061-1064

19. Yarmolinsky MB. (1995) Programmed cell death in bacterial populations [comment]. Science 267: 836-837

20. Kobayashi I. (1998) Selfishness and death: raison d'etre of restriction, recombination and mitochondria. Trends Genet. 14: 368-374

21. Welburn SC and Maudlin I (1997) Control of Trypanosoma brucei brucei infections in tsetse, Glossina morsitans. Med. Vet. Entomol. 11: 286-289

22. Welburn SC, Maudlin I and Ellis DS (1989) Rate of trypanosome killing by lectins in midguts of different species and strains of Glossina. Med. Vet. Entomol. 3:7782

23. Ameisen JC, Idziorek T, Billaut-Mulot O, Loyens M, Tissier J-P, Potentier A and Ouaissi A (1995) Apoptosis in a unicellular eukaryote (Trypanosoma cruzi): implications for the evolutionary origin and role of programmed cell death in the control of cell proliferation, differentiation and survival. Cell Death Differ. 2: 285300

24. Pearson TW, Beecroft RP, Welburn SC, Ruepp S, Roditi I, Hwa KY, Englund PT, Wells CW and Murphy NB (2000) The major cell surface glycoprotein procyclin is a receptor for induction of a novel form of cell death in African trypanosomes in vitro. Mol. Biochem. Parasitol. 111: 333-349
25. Welburn SC, Lillico S and Murphy NB (1999) Programmed cell death in procyclic form Trypanosoma brucei rhodesiense-identification of differentially expressed genes during con A induced death. Mem. Inst. Oswaldo Cruz 94: 229-234

26. Ridgley EL, Xiong ZH and Ruben L (1999) Reactive oxygen species activate a Ca2+-dependent cell death pathway in the unicellular organism Trypanosoma brucei brucei. Biochem. J. 340: 33-40

27. Moreira ME, Del Portillo HA, Milder RV, Balanco JM and Barcinski MA (1996) Heat shock induction of apoptosis in promastigotes of the unicellular organism Leishmania (Leishmania) amazonensis. J. Cell Physiol. 167: 305-313

28. Billaut-Mulot O, Fernandez-Gomez R, Loyens M and Ouaissi A (1996) Trypanosoma cruzi elongation factor 1-alpha: nuclear localization in parasites undergoing apoptosis. Gene 174: 19-26

29. Welburn SC and Murphy NB (1998) Prohibitin and RACK homologues are upregulated in trypanosomes induced to undergo apoptosis and in naturally occurring terminally differentiated forms. Cell Death Differ. 5: 615-622

30. Maercker C, Kortwig H, Nikiforov MA, Allis CD and Lipps HJ (1999) A nuclear protein involved in apoptotic-like DNA degradation in Stylonychia: implications for similar mechanisms in differentiating and starved cells. Mol. Biol. Cell. 10: 3003-3014

31. Aravind L, Dixit VM and Koonin EV (2001) Apoptotic molecularmachinery: vastly increased complexity in vertebrates revealed by genome comparisons. Science 291: $1279-1284$

32. Aravind L, Dixit VM and Koonin EV (1999) The domains of death: evolution of the apoptosis machinery. Trends Biochem. Sci. 24: 47-53

33. Uren AG, O'Rourke K, Aravind LA, Pisabarro MT, Seshagiri S, Koonin EV and Dixit VM (2000) Identification of paracaspases and metacaspases: two ancient families of caspase-like proteins, one of which plays a key role in MALT lymphoma. Mol. Cell. 6: 961-967

34. Arnoult D, Akarid K, Grodet A, Petit PX, Estaquier J and Ameisen JC (2002) On the evolution of programmed cell death: apoptosis of the unicellular eukaryote Leishmania major involves cysteine proteinase activation and mitochondrion permeabilization. Cell Death Differ. 9: 65-81

35. Lee N, Bertholet S, Debrabant A, Muller J, Duncan R and Nakhasi HL (2002) Programmed cell death in the unicellular protozoan parasite Leishmania. Cell Death Differ. 9: 53-64

36. Leist $M$ and Jaattela $M$ (2001) Four deaths and a funeral: from caspases to alternative mechanisms. Nat. Rev. Mol. Cell Biol. 2: 589-598

37. Telford DJ and Stewart BW (1989) Micrococcal nuclease: its specificity and use for chromatin analysis. Int. J. Biochem. 21: 127-137

38. Ishisaka R, Kanno t, Akiyama J, Yoshioka T, Utsumi K and Utsumi T (2001) Activation of caspase-3 by lysosomal cysteine proteases and its role in $2,2^{\prime}$ azobis-(2-amidinopropane)dihydrochloride (AAPH)-induced apoptosis in HL-60 cells. J. Biochem. (Tokyo) 129: 35-41

39. Mottram JC, Souza AE, Hutchison JE, Carter R, Frame MJ and Coombs GH (1996) Evidence from disruption of the Imcpb gene array of Leishmania mexicana that cysteine proteinases are virulence factors. Proc. Natl. Acad. Sci. USA 93: $6008-6013$

40. BalkJ, Leaver CJ and McCabe PF (1999) Translocation of cytochrome c from the mitochondria to the cytosol occurs during heat-induced programmed cell death in cucumber plants. FEBS Lett. 463: 151-154

41. Mauel $\mathrm{J}$ and Ransijn A (1997) Leishmania spp.: mechanisms of toxicity of nitrogen oxidation products. Exp. Parasitol. 87: 98-111

42. Lecoeur H, Prevost M and Gougeon M (2001) Oncosis is associated with exposure of phosphatidylserine residues on the outside layer of the plasma membrane: a reconsideration of the specificity of the annexin $\mathrm{V} /$ propidium iodide assay. Cytometry 44: 65-72

43. Marini Mand Musiani D (1998) Micromolar zinc affects endonucleolytic activity in hydrogen peroxide-mediated apoptosis. Exp. Cell. Res. 239: 393-398

44. Widlak P, Li P, Wang X and Garrard WT (2000) Cleavage preferences of the apoptotic endonuclease DFF40 (caspase-activated DNase or nuclease) on naked DNA and chromatin substrates. J. Biol. Chem. 275: 8226-8232

45. Gaido ML and Cidlowski JA(1991) Identification, purification, and characterization of a calcium-dependent endonuclease (NUC18) from apoptotic rat thymocytes. NUC18 is not histone H2B. J. Biol. Chem. 266: 18580-18585

46. Sun DY, Jiang S, Zheng LM, Ojcius DM and Young JD (1994) Separate metabolic pathways leading to DNA fragmentation and apoptotic chromatin condensation. J. Exp. Med. 179: 559-568 
47. Cohen JJ and Duke RC (1984) Glucocorticoid activation of a calcium-dependent endonuclease in thymocyte nuclei leads to cell death. J. Immunol. 132: 38-42

48. Zamzami N and Kroemer G (1999) Condensed matter in cell death. Nature 401 $127-128$

49. Zhang C, Robertson MJ and Schlossman SF (1995) A triplet of nuclease proteins (NP42-50) is activated in human Jurkat cells undergoing apoptosis. Cell Immunol. 165: 161-167

50. Warbrick E. (1996) A new twist to the tale? Apoptosis. Curr. Biol. 6: 1057-1059

51. Debrabant A, Ghedin E and Dwyer DM (2000) Dissection of the functional domains of the Leishmania surface membrane 3 -nucleotidase/nuclease, a unique member of the class I nuclease family. J. Biol. Chem. 275: 16366 - 16372

52. Glaser TA, Wells SJ, Spithill TW, Pettitt JM, Humphris DC and Mukkada AJ (1990) Leishmania major and L. donovani: a method for rapid purification of amastigotes. Exp. Parasitol. 71: 343-345

53. Chandler JM, Cohen GM and MacFarlane M (1998) Different subcellular distribution of caspase-3 and caspase-7 following Fas-induced apoptosis in mouse liver. J. Biol. Chem. 273: 10815-10818

54. Mottram JC, Brooks DR and Coombs GH (1998) Roles of cysteine proteinases of trypanosomes and Leishmania in host-parasite interactions. Curr. Opin. Microbiol. 1: 455-460

55. Alves LC, St. Hilaire PM, Meldal M, Sanderson SJ, Mottram JC, Coombs GH, Juliano $L$ and Juliano MA (2001) Identification of peptides inhibitory to recombinant cysteine proteinase, $\mathrm{CPB}$, of Leishmania mexicana. Mol. Biochem. Parasitol. 114: 81-88

56. Alves LC, Judice WAS, St. Hilaire PM, Meldal M, Sanderson SJ, Mottram JC, Coombs GH, Juliano L and Juliano MA (2001) Substrate specificity of recombinant cysteine proteinase, $\mathrm{CPB}$, of Leishmania mexicana. Mol. Biochem. Parasitol. 116: 1-9

57. Bart G, Frame MJ, Carter R, Coombs GH and Mottram JC (1997) Cathepsin Blike cysteine proteinase-deficient mutants of Leishmania mexicana. Mol. Biochem. Parasitol. 88: 53-61

58. Frame MJ, Mottram JC and Coombs GH (2000) Analysis of the roles of cysteine proteinases of Leishmania mexicana in the host-parasite interaction. Parasitology 121: 367-377

59. Roberts LR, Adjei PN and Gores GJ (1999) Cathepsins as effector proteases in hepatocyte apoptosis. Cell. Biochem. Biophys. 30: 71-88

60. Shibata M, Kanamori S, Isahara K, Ohsawa Y, Konishi A, Kametaka S, Watanabe T, Ebisu S, Ishido K, Kominami E and Uchiyama Y (1998) Participation of cathepsins $B$ and $D$ in apoptosis of $P C 12$ cells following serum deprivation. Biochem. Biophys. Res. Commun. 251: 199-203
61. Vancompernolle K, Van Herreweghe F, Pynaert G, Van de Craen M, De Vos K, Totty N, Sterling A, Fiers W, Vandenabeele Pand Grooten J (1998) Atractylosideinduced release of cathepsin $\mathrm{B}$, a protease with caspase-processing activity. FEBS Lett. 438: 150-158

62. Bart G, Coombs GH and Mottram JC (1995) Isolation of Imcpc, a gene encoding a Leishmania mexicana cathepsin-B-like cysteine proteinase. Mol. Biochem. Parasitol. 73: 271-274

63. Sperandio S, de Belle I and Bredesen DE (2000) An alternative, nonapoptotic form of programmed cell death. Proc. Natl. Acad. Sci. USA 97: 14376-14381

64. Das M, Mukherjee SB and Shaha C (2001) Hydrogen peroxide induces apoptosis-like death in Leishmania donovani promastigotes. J. Cell Science 114 2461-2469

65. Sereno D, Holzmuller P, Mangot I, Cuny G, Ouaissi A and Lemesre JL (2001) Antimonial-mediated DNA fragmentation in Leishmania infantum amastigotes. Antimicrob. Agents Chemother. 45: 2064-2069

66. Belli SI. (2000) Chromatin remodelling during the life cycle of trypanosomatids Int. J. Parasitol. 30: 679-687

67. Alexander J, Coombs GH and Mottram JC (1998) Leishmania mexicana cysteine proteinase-deficient mutants have attenuated virulence for mice and potentiatea Th1 response. J. Immunol. 161: 6794-6801

68. Solioz N, Blum-Tirouvanziam U, Jacquet R, Rafati S, Corradin G, Mauel J and Fasel $\mathrm{N}$ (1999) The protective capacities of histone $\mathrm{H} 1$ against experimental murine cutaneous leishmaniasis. Vaccine 18: 850-859

69. Schlimme W, Burri M, Bender K, BetschartB and Hecker H (1993) Trypanosoma brucei brucei: differences in the nuclear chromatin of bloodstream forms and procyclic culture forms. Parasitology 107: 237-247

70. Noll TM, Desponds C, Belli SI, Glaser TA and Fasel NJ (1997) Histone H1 expression varies during the Leishmania major life cycle. Mol. Biochem. Parasitol. 84: 215-227

71. Kataoka T, Holler N, Micheau O, Martinon F, Tinel A, Hofmann K and Tschopp J (2001) Bcl-rambo, a novel Bcl-2 homologue that induces apoptosis via its unique C-terminal extension. J. Biol. Chem. 276: 19548-19554

72. Bodmer JL, Holler N, Reynard S, Vinciguerra P, Schneider P, Juo P, Blenis J and Tschopp J (2000) TRAIL receptor-2 signals apoptosis through FADD and caspase-8. Nat. Cell. Biol. 2: 241-243

73. Corradin S, Mauel J, Ransijn A, Sturzinger C and Vergeres G (1999) Downregulation of MARCKS-related protein (MRP) in macrophages infected with Leishmania. J. Biol. Chem. 274: 16782-16787 